\title{
Effectiveness of endoscopic surgery for supratentorial hypertensive intracerebral hemorrhage: a comparison with craniotomy
}

\author{
*Xinghua Xu, MD, Xiaolei Chen, MD, Fangye Li, MD, Xuan Zheng, MD, Qun Wang, MD, \\ Guochen Sun, MD, Jun Zhang, MD, and Bainan Xu, MD \\ Department of Neurosurgery, Chinese PLA General Hospital, Beijing, China
}

\begin{abstract}
OBJECTIVE The goal of this study was to investigate the effectiveness and practicality of endoscopic surgery for treatment of supratentorial hypertensive intracerebral hemorrhage $(\mathrm{HICH})$ compared with traditional craniotomy.

METHODS The authors retrospectively analyzed 151 consecutive patients who were operated on for treatment of supratentorial HICH between January 2009 and June 2014 in the Department of Neurosurgery at Chinese PLA General Hospital. Patients were separated into an endoscopy group (82 cases) and a craniotomy group (69 cases), depending on the surgery they received. The hematoma evacuation rate was calculated using 3D Slicer software to measure the hematoma volume. Comparisons of operative time, intraoperative blood loss, Glasgow Coma Scale score 1 week after surgery, hospitalization time, and modified Rankin Scale score 6 months after surgery were also made between these groups.
\end{abstract}

RESULTS There was no statistically significant difference in preoperative data between the endoscopy group and the craniotomy group $(p>0.05)$. The hematoma evacuation rate was $90.5 \% \pm 6.5 \%$ in the endoscopy group and $82.3 \% \pm$ $8.6 \%$ in the craniotomy group, which was statistically significant $(p<0.01)$. The operative time was $1.6 \pm 0.7$ hours in the endoscopy group and $5.2 \pm 1.8$ hours in the craniotomy group $(p<0.01)$. The intraoperative blood loss was 91.4 $\pm 93.1 \mathrm{ml}$ in the endoscopy group and $605.6 \pm 602.3 \mathrm{ml}$ in the craniotomy group $(p<0.01)$. The 1-week postoperative Glasgow Coma Scale score was $11.5 \pm 2.9$ in the endoscopy group and $8.3 \pm 3.8$ in the craniotomy group $(p<0.01)$. The hospital stay was $11.6 \pm 6.9$ days in the endoscopy group and $13.2 \pm 7.9$ days in the craniotomy group $(p<0.05)$. The mean modified Rankin Scale score 6 months after surgery was $3.2 \pm 1.5$ in the endoscopy group and $4.1 \pm 1.9$ in the craniotomy group $(p<0.01)$. Patients had better recovery in the endoscopy group than in the craniotomy group. Data are expressed as the mean $\pm \mathrm{SD}$.

CONCLUSIONS Compared with traditional craniotomy, endoscopic surgery was more effective, less invasive, and may have improved the prognoses of patients with supratentorial $\mathrm{HICH}$. Endoscopic surgery is a promising method for treatment of supratentorial $\mathrm{HICH}$. With the development of endoscope technology, endoscopic evacuation will become more widely used in the clinic. Prospective randomized controlled trials are needed.

https://thejns.org/doi/abs/10.3171/2016.10.JNS161589

KEY WORDS endoscopic surgery; hypertensive intracerebral hemorrhage; craniotomy, vascular disorders

$\mathrm{S}$ PONTANEOUS intracerebral hemorrhages (ICHs) are responsible for $10 \%-30 \%$ of all strokes yet are one of the leading causes of stroke-related mortality and morbidity..$^{10}$ Hypertensive ICH (HICH) is the most common type of ICH, accounting for approximately $70 \%$ of all ICHs. ${ }^{14} \mathrm{HICH}$ is a common neurological emergency characterized by high fatality and disability rates. The me- dian 30-day mortality rate after $\mathrm{HICH}$ is approximately $40 \% .{ }^{21,25}$ Many survivors remain severely disabled and therefore pose a huge burden on society and families?

Surgical hematoma evacuation and conservative therapy are the main treatments for ICH. Theoretically, surgical removal can facilitate the survival of a penumbra of functionally impaired but potentially viable surrounding tissue,

ABBREVIATIONS GCS = Glasgow Coma Scale; $\mathrm{HICH}=$ hypertensive intracerebral hemorrhage; $\mathrm{ICH}=$ intracerebral hemorrhage; mRS = modified Rankin Scale; $\mathrm{STICH}=$ Surgical Trial in Intracerebral Haemorrhage.

SUBMITTED June 15, 2016. ACCEPTED October 31, 2016.

INCLUDE WHEN CITING Published online April 7, 2017; DOI: 10.3171/2016.10.JNS161589.

* Drs. X. Xu and Chen contributed equally to this work. 


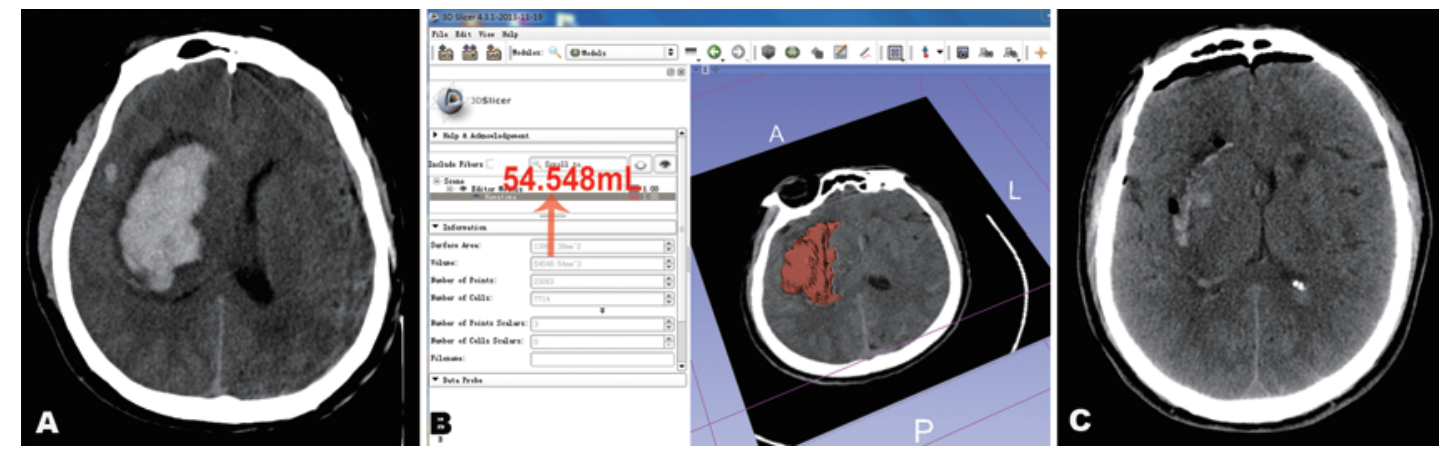

FIG. 1. Volume measurement of hematoma with 3D Slicer. A: A preoperative CT scan confirmed a right basal ganglia hemorrhage. B: 3D reconstruction and volume measurement of hematoma with 3D Slicer. C: A postoperative CT scan showed that most of the hematoma had been evacuated. Figure is available in color online only.

by decreasing secondary brain edema resulting from the breakdown of blood and other neurotoxic chemicals. ${ }^{12,22}$ Hematoma removal also directly addresses the problem of local mass effect that leads to brain tissue damage. ${ }^{28} \mathrm{Nev}-$ ertheless, the effectiveness of craniotomy for the treatment of ICH remains controversial, despite having been repeatedly evaluated during the past 4 decades. ${ }^{1,26,34}$ With the development of neuroendoscopic techniques, endoscopic hematoma evacuation is proving to be effective and may have some advantages compared with craniotomy. $1,17,18,30$ Endoscopic hematoma evacuation may be theoretically attractive and may be advocated as the primary treatment of choice; however, its effectiveness remains unclear. ${ }^{8,32} \mathrm{We}$ conducted a comparative study of endoscopic hematoma evacuation using a newly developed endoscope introducer versus traditional craniotomy evacuation of hematoma.

The volume of hematoma has been validated as an important independent predictor for prognosis of $\mathrm{ICH} .{ }^{20,33}$ The Tada $(\mathrm{ABC} / 2)$ formula has been widely used for bedside estimation of hematoma volume in almost all clinical studies. However, the $\mathrm{ABC} / 2$ formula has a certain range of error, especially in cases of irregular or large hematomas. ${ }^{29}$ Therefore, 3D Slicer, a precise and freely available platform, was applied for the measurement of hematoma volume in this study.

\section{Methods \\ Patient Selection}

The study group (endoscopy group) consisted of 82 consecutive adult patients with supratentorial HICH treated between June 2011 and June 2014. The endoscopy group was matched to a historical control group (craniotomy group), a series of 69 consecutive patients treated by craniotomy at the Chinese PLA General Hospital between January 2009 and June 2012. The preoperative and postoperative treatments, including blood pressure management, were identical for all 151 patients. The inclusion criteria were spontaneous supratentorial HICH confirmed on brain CT scans with hematoma volume $>20 \mathrm{ml}$, admission to hospital within 48 hours of ictus, and adultage patients with a Glasgow Coma Scale (GCS) score $\geq 5$. Some patients underwent CT angiography to exclude underlying structural vascular disease. The exclusion criteria were hemorrhage caused by tumor, trauma, coagulopathy, aneurysm, arteriovenous malformation, hemorrhage after infarction, and use of antiplatelet or anticoagulant drugs over a long period of time. Inclusion and exclusion criteria were the same for both groups. The study was approved by the Chinese PLA General Hospital medical ethics committee.

\section{Calculation of Hematoma Volume}

In all patients, a brain CT scan was obtained before and 24 hours after surgery. CT image data sets were acquired in the DICOM format. The data were transferred to a personal computer (Intel Core i5 CPU, $2 \times 2.5 \mathrm{GHz}, 4 \mathrm{~GB}$ RAM) and then assessed with 3D Slicer. Hematomas were automatically identified pixel by pixel in each slice after setting the threshold range at 50-100 Hounsfield units. Then, a 3D model was constructed and the hematoma volume was calculated by the accumulating volume of the pixels (Fig. 1). The hematoma evacuation rate was defined as follows: (preoperative volume - postoperative volume)/ (preoperative volume) $\times 100 \%$.

\section{Surgical Technique}

The surgical procedure was performed while the patient was under general anesthesia. For the endoscopy group, a 3-cm skin incision was made according to the position of the hematoma on CT scan. We used a bur hole over the coronal suture for anterior basal ganglia hemorrhages that were not elongated but rather were more spherical. A parietooccipital bur hole was created to treat posterior basal ganglia and thalamic hemorrhages. In cases involving superficial lobar hemorrhages, we commonly use a bur hole directly over the hematoma where the lesion is closest to the surface. ${ }^{3}$ The dura mater was coagulated and incised in a cruciate fashion. We used our self-developed endoscopic puncture and working channel system (patent number 201210066281.1, Beijing Jin Cheng Medical Technology Co.) to create the operating space for the neuroendoscope. After the puncturing needle was positioned in the predetermined center of the hematoma, the needle core was removed and suction was applied with a 10-ml syringe to reduce intracranial pressure and to determine whether the puncture lever was in place. Next, a transparent sheath was introduced to an expected depth along the puncturing needle (Fig. 2). Through the transparent sheath, 

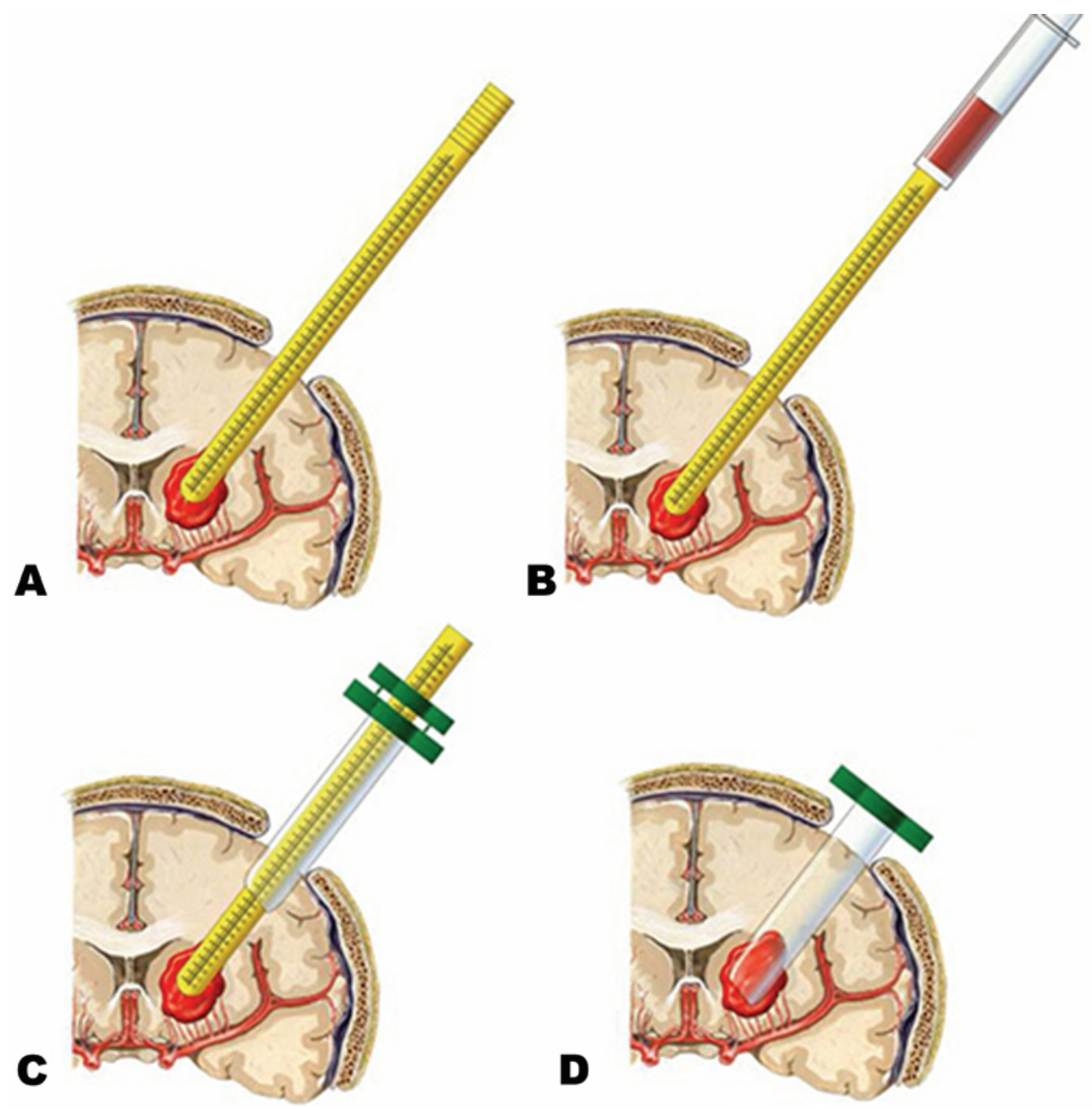

FIG. 2. Schematic diagrams of the hematoma puncture process in the endoscopy group. A: Hematoma puncture with a blunt puncturing needle. B: Suction of the hematoma with a syringe. C and D: Placement of the transparent endoscopic sheath along the puncturing needle. Copyright Xiaolei Chen. Published with permission. Figure is available in color online only.

a neuroendoscope (diameter $3.6 \mathrm{~mm}, 0^{\circ}$, Karl Storz) was inserted and a metal suction catheter was used to evacuate the hematoma (Fig. 3). For the craniotomy group, a traditional craniotomy was performed to evacuate the hematoma. After opening the dura, the neurosurgeon accessed the hematoma cavity via a transcortical approach using microscopic assistance and removed the hematoma. All patients received the best medical treatment after surgery. A postoperative CT scan was obtained in every patient 24 hours after surgery to evaluate for any residual hematoma.

\section{Statistical Analysis}

All statistical analyses were performed with SPSS statistics version 21 (IBM Corp.). After confirmation of distribution, data are expressed as the mean $\pm \mathrm{SD}$. An unpaired t-test, rank-sum test, or $\chi^{2}$ test was used for comparison between groups, as appropriate. A p value $<0.05$ was considered statistically significant.

\section{Results}

\section{Baseline Information}

A total of 151 consecutive patients were enrolled in this study: 82 in the endoscopy group and 69 in the historical control group (craniotomy group). Baseline characteristics are summarized in Table 1. The average age of patients was 52.9 years in the endoscopy group and 53.8 years in the craniotomy group $(\mathrm{p}>0.05)$. The mean admission GCS score was 7.9 for the endoscopy group and 7.8 for the craniotomy group $(p>0.05)$. The mean time from ictus to surgery was 15.6 hours in the endoscopy group and 13.7 hours in the craniotomy group $(p>0.05)$. In the endoscopy group, the mean hematoma volume was 55.2 $\mathrm{ml}$, whereas in the craniotomy group, it was $55.9 \mathrm{ml}(\mathrm{p}>$ $0.05)$. Most hematomas were located at the basal ganglia in both the endoscopy group (65 of 82) and the craniotomy group (52 of 69) ( $p>0.05)$. There were no statistically significant differences between these groups with respect to the average age of patients, sex ratio, GCS score at admission, time to surgery, preoperative hematoma volume, and hematoma location.

\section{Clinical Results}

The general clinical results are presented in Table 2 . The hematoma evacuation rate of the endoscopy group was significantly higher than that of the craniotomy group 


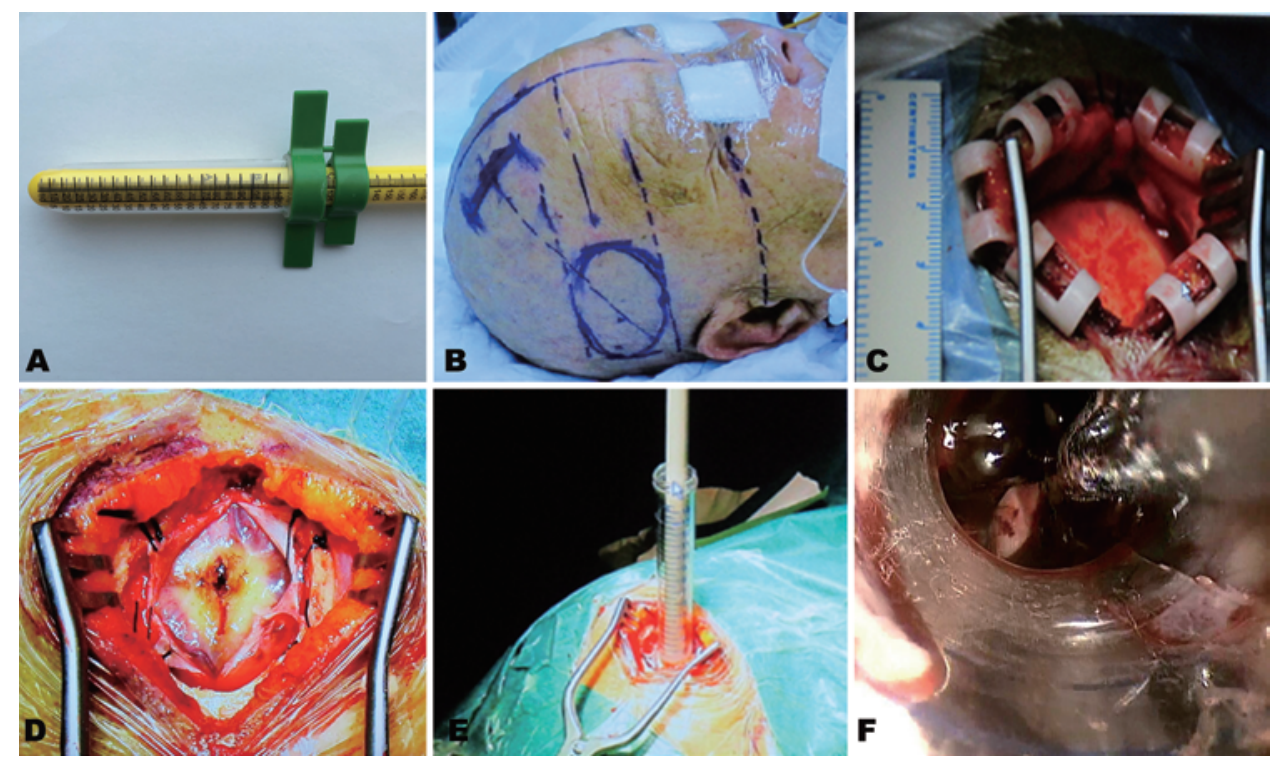

FIG. 3. Endoscopic surgery. A: A newly developed endoscopic sheath. B: An analog incision and puncture direction. C: A small bone window craniotomy. D: The dura mater is coagulated and incised. E: Hematoma puncture. F: Hematoma evacuation under the endoscope. Figure is available in color online only.

(90.5\% vs $82.3 \%$; p < 0.01) (Fig. 4). The operative time was 1.6 hours in the endoscopy group and 5.2 hours in the craniotomy group $(\mathrm{p}<0.01)$. The intraoperative blood loss of the endoscopy group was far less than that of the craniotomy group (91.4 vs $605.6 \mathrm{ml} ; \mathrm{p}<0.01$ ). The mean GCS score 1 week after surgery was 11.5 in the endoscopy group and 8.3 in the craniotomy group $(\mathrm{p}<0.01)$. The mean length of hospital stay was shorter in the endoscopy group than in the craniotomy group (11.6 vs 13.2 days; $p$ $<0.05$ ). Two patients in the endoscopy group had rebleeding and 6 patients in the craniotomy group had rebleeding $(\mathrm{p}>0.05)$. The hospital mortality rate was $7.3 \%$ in the endoscopy group and $14.5 \%$ in the craniotomy group; the difference was not statistically significant $(p>0.05)$.

Patients were followed up by telephone at 6 months after surgery. Four (4.9\%) patients in the endoscopy group and $5(7.2 \%)$ patients in the craniotomy group were lost to follow-up. The rate of patients who were lost to follow-up was within the permissible range. Of the patients who were

TABLE 1. General characteristics of all patients

\begin{tabular}{lccc}
\hline \multirow{2}{*}{ Variable } & \multicolumn{2}{c}{ Patient Group } & \\
\cline { 2 - 3 } & $\begin{array}{c}\text { Endoscopy, } \\
n=82\end{array}$ & $\begin{array}{c}\text { Craniotomy, } \\
n=69\end{array}$ & $\begin{array}{c}p \\
\text { Value }\end{array}$ \\
\hline Average age, yrs* & $52.9 \pm 12.3$ & $53.8 \pm 13.5$ & 0.152 \\
\hline Male, no. (\%) & $58(70.7)$ & $46(66.7)$ & 0.526 \\
\hline GCS score at admission* $^{*}$ & $7.9 \pm 2.2$ & $7.8 \pm 3.1$ & 0.892 \\
\hline Time to surgery, hrs* & $15.6 \pm 14.9$ & $13.7 \pm 11.6$ & 0.381 \\
\hline Mean preop hematoma vol, $\mathrm{ml}^{*}$ & $55.2 \pm 28.4$ & $55.9 \pm 27.6$ & 0.973 \\
\hline Hematoma location, no. (\%) & & & 0.696 \\
\hline Basal ganglia & $65(79.3)$ & $52(75.4)$ & \\
\hline Subcortex & $17(20.7)$ & $17(24.6)$ & \\
\hline * & &
\end{tabular}

* Values are expressed as the mean \pm SD. followed up in the endoscopy group, 5 had no symptoms, 12 had no significant disability, 13 had a slight disability, 17 had moderate disability, 8 had moderately severe disability, 8 had severe disability, and 15 had died. Of the patients who were followed up in the craniotomy group, 2 had no symptoms, 2 had no significant disability, 7 had a slight disability, 10 had moderate disability, 16 had moderately severe disability, 9 had severe disability, and $18 \mathrm{had}$ died. The mean modified Rankin Scale (mRS) score of patients was 3.2 in the endoscopy group and 4.1 in the craniotomy group; the difference was statistically significant ( $p<0.01$; Fig. 5). The endoscopy group had better neurological recovery compared with the craniotomy group.

\section{Discussion}

$\mathrm{HICH}$ is a common neurological disease characterized by poor prognosis and outcomes. Only approximately $20 \%$ of patients with $\mathrm{HICH}$ can live on their own posthemorrhage. ${ }^{3}$ The management of HICH is still contro-

TABLE 2. Comparison of general clinical results between the endoscopy and craniotomy groups

\begin{tabular}{|c|c|c|c|}
\hline \multirow[b]{2}{*}{ Variable } & \multicolumn{2}{|c|}{ Patient Group } & \multirow[b]{2}{*}{$\begin{array}{c}p \\
\text { Value }\end{array}$} \\
\hline & $\begin{array}{c}\text { Endoscopy, } \\
\qquad \mathrm{n}=82\end{array}$ & $\begin{array}{c}\text { Craniotomy, } \\
n=69\end{array}$ & \\
\hline Clearance rate, $\%{ }^{*}$ & $90.5 \pm 6.5$ & $82.3 \pm 8.6$ & 0.001 \\
\hline Op time, hrs* & $1.6 \pm 0.7$ & $5.2 \pm 1.8$ & 0.001 \\
\hline Intraop blood loss, $\mathrm{ml}^{*}$ & $91.4 \pm 93.1$ & $605.6 \pm 602.3$ & 0.001 \\
\hline Postop GCS score at $1 \mathrm{wk}^{*}$ & $11.5 \pm 2.9$ & $8.3 \pm 3.8$ & 0.001 \\
\hline Hospital stay, days* & $11.6 \pm 6.9$ & $13.2 \pm 7.9$ & 0.035 \\
\hline Hospital mortality, no. (\%) & $6(7.3)$ & $10(14.5)$ & 0.161 \\
\hline mRS score 6 mos postop* & $3.2 \pm 1.5$ & $4.1 \pm 1.9$ & 0.004 \\
\hline
\end{tabular}

\footnotetext{
* Values are expressed as the mean $\pm \mathrm{SD}$.
} 


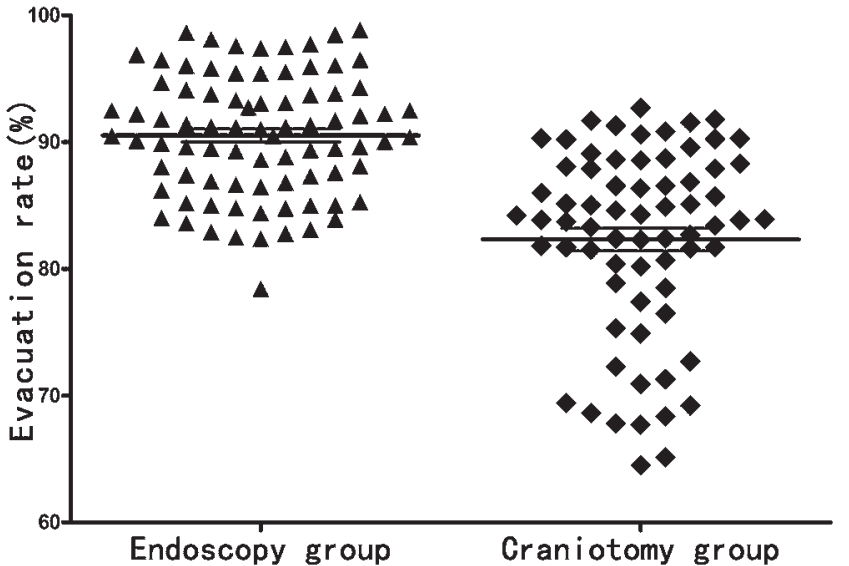

FIG. 4. Comparison of the hematoma evacuation rates between the endoscopy and craniotomy groups. Endoscopic surgery has a much higher hematoma evacuation rate than craniotomy.

versial, and the role of surgery in the treatment of $\mathrm{HICH}$ has not been fully established. ${ }^{8}$ Surgical evacuation of the intracerebral hematoma is based on the idea of reducing mass effect and thereby decreasing intracranial pressure, improving regional blood flow, and restricting the release of toxic breakdown products released by the clot. ${ }^{9}$ Possible negative side effects include the additional trauma caused by the procedure itself and a possibly increased risk of rebleeding by removing the tamponade of the hematoma.

Thus far, multiple clinical trials have failed to find a consistent clinical benefit of hemorrhage evacuation..$^{26,34}$ Results of the Surgical Trial in Intracerebral Haemorrhage (STICH) trial indicated that patients with spontaneous supratentorial ICH in neurosurgical units showed no overall benefit from early surgery when compared with initial conservative treatment. ${ }^{13}$ However, in this trial, operative intervention occurred in approximately one-quarter of patients in the initial conservative treatment group, and these crossovers from conservative treatment to surgery make interpretation of the results complicated. The STICH II trial, a study based on the results of a subgroup analysis from the STICH trial, confirmed that early surgery did not increase the rate of death or disability at 6 months and might have had a small but clinically relevant survival advantage for patients with spontaneous superficial ICH without intraventricular hemorrhage. Moreover, almost all of the patients in STICH II who underwent surgery had craniotomy. Minimal-access techniques such as endoscopic surgery might be more beneficial, and studies that compare endoscopic procedures with conventional surgery are lacking.

Endoscopic surgery is a relatively new method for treatment of $\mathrm{HICH} .{ }^{1}$ In endoscopic evacuation, a small bur hole is created, and an endoscope $5-8 \mathrm{~mm}$ in diameter is inserted through normal brain tissue into the hematoma. Suction and irrigation are applied to remove the hematoma. The brain is then visualized via the endoscope to determine the site of bleeding and to assess the amount of hematoma. As shown by our results, endoscopic surgery has some advantages compared with craniotomy, such as minimal invasiveness, high evacuation rate, shorter op-

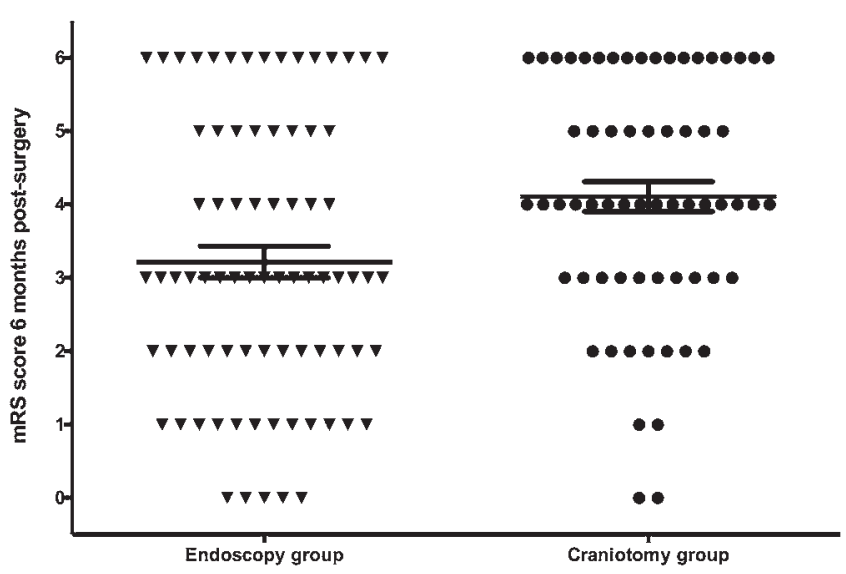

FIG. 5. Comparison of mRS scores at 6 months after surgery. Patients in the endoscopy group had a lower mRS score, indicating that endoscopic surgery results in better functional recovery.

erative time, and better follow-up outcomes. Results of our study showed that the hematoma evacuation rate in the endoscopy group was much higher than that in the craniotomy group $(90.5 \%$ vs $82.3 \% ; \mathrm{p}<0.01)$, similar to

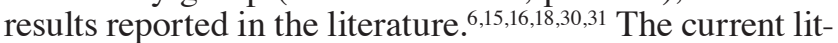
erature on endoscopic evacuation of ICH is summarized in Table 3.

In our study, we used an independently developed 10$\mathrm{mm}$ transparent endoscope sheath to create a minimally invasive surgical channel to the hematoma. This new application has several benefits. First, transparency of the introducer helped us to better distinguish the hematoma cavity from the brain parenchyma. Additionally, the puncture process was accomplished in 2 steps. As a result, we could easily confirm whether the puncture direction was satisfactory and avoid brain hernia induced by increased intracranial pressure. Finally, it was easy to verify whether all of the hematoma had been evacuated with use of a transparent introducer. Our results indicate that endoscopic surgery is safe and feasible. The improved mRS score at 6 months after surgery indicates that early endoscopic hematoma evacuation may improve the prognosis of patients with $\mathrm{HICH}$.

Accurate measurement of hematoma volume is clinically important because it has been widely used in correlation with treatment strategy, functional outcome, and mortality. Precise assessment of hematoma volume is also critical for clinical trials, in which change in hematoma volume may be a surrogate end point. ${ }^{24}$ In almost all previous studies, hematoma volumes have been estimated using the $\mathrm{ABC} / 2$ formula. However, the $\mathrm{ABC} / 2$ formula has a certain range of estimation error, which could be up to nearly $40 \%$ for some specific hematomas. ${ }^{29}$ This error rate is unacceptable for research purposes. Therefore, we used a precise and freely available software, 3D Slicer, to measure the volume of hematomas. Using this method can make results from different clinical trials easier to compare, which is important for the standardization of research.

However, it should be noted that our study has limitations. First, data were collected retrospectively, and there might have been selection bias. Second, the patients in our 
TABLE 3. Summary of the literature on endoscopic evacuation of ICH

\begin{tabular}{|c|c|c|c|c|c|}
\hline $\begin{array}{l}\text { Authors } \\
\& \text { Year }\end{array}$ & $\begin{array}{l}\text { Study } \\
\text { Design }\end{array}$ & Group & $\begin{array}{l}\text { No. of } \\
\text { Pts }\end{array}$ & $\begin{array}{l}\text { Hemorrhage } \\
\text { Location }\end{array}$ & Outcome \\
\hline $\begin{array}{l}\text { Auer et al., } \\
1989\end{array}$ & Prospective & Endo vs medi & 100 & Supratentorial only & Endo had a lower mortality rate \& improved outcomes \\
\hline $\begin{array}{l}\text { Cho et al., } \\
2006\end{array}$ & Prospective & $\begin{array}{l}\text { Endo vs stereo } \\
\text { vs crani }\end{array}$ & 90 & Basal ganglia & Endo had improved outcome \& was more cost-effective \\
\hline $\begin{array}{l}\text { Nishihara et } \\
\text { al., } 2007\end{array}$ & Case-control & Endo vs stereo & 47 & Any & $\begin{array}{l}\text { Endo resulted in better outcomes, reduced op time, \& } \\
\text { shorter ICU stay }\end{array}$ \\
\hline $\begin{array}{l}\text { Chen et al., } \\
2007\end{array}$ & Case series & Endo only & 7 & Thalamus & $\begin{array}{l}\text { Endo improved the efficiency of thalamic hematoma evacua- } \\
\text { tion \& prevented shunt-dependent hydrocephalus }\end{array}$ \\
\hline $\begin{array}{l}\text { Nagasaka et } \\
\text { al., } 2011\end{array}$ & Retrospective & Endo vs crani & 43 & $\begin{array}{l}\text { Putamen, thalamus, } \\
\text { or cerebellum }\end{array}$ & $\begin{array}{l}\text { Endo resulted in a higher success rate, greater GCS score } \\
\text { improvement, \& a lower mortality rate }\end{array}$ \\
\hline $\begin{array}{l}\text { Kuo et al., } \\
2011\end{array}$ & Retrospective & Endo only & 68 & Supratentorial only & $\begin{array}{l}\text { Endo had a good evacuation rate (mean } 93 \% \text { ) w/ low mor- } \\
\text { bidity \& mortality rates }\end{array}$ \\
\hline $\begin{array}{l}\text { Basaldella et } \\
\text { al., } 2012\end{array}$ & Retrospective & $\begin{array}{l}\text { Endo + EVD vs } \\
\text { EVD alone }\end{array}$ & 96 & Unspecified & $\begin{array}{l}\text { Endoscopy + EVD did not significantly affect outcomes at } \\
\qquad 1 \mathrm{yr}\end{array}$ \\
\hline $\begin{array}{l}\text { Wang et al., } \\
2015\end{array}$ & Retrospective & Endo vs crani & 21 & Supratentorial only & $\begin{array}{l}\text { Endo reduced ICU stay, but had no effect on 6-mo out- } \\
\text { comes }\end{array}$ \\
\hline $\begin{array}{l}\text { Sun et al., } \\
\qquad 2016\end{array}$ & Retrospective & Endo only & 25 & Supratentorial only & $\begin{array}{l}\text { Augmented reality helped endoscopic surgery to achieve } \\
\text { satisfactory hematoma removal }\end{array}$ \\
\hline
\end{tabular}

crani = craniotomy; endo = endoscopic evacuation; EVD = external ventricular drainage; medi = medical treatment; pts = patients; stereo = stereotactic evacuation.

study had larger hematoma volumes compared with patients in previous studies.

\section{Conclusions}

Our results showed that endoscopic surgery significantly increased the hematoma evacuation rate and improved $\mathrm{mRS}$ scores at 6 months after surgery in patients with $\mathrm{HICH}$. Our findings indicate that endoscopic surgery is safe, feasible, and may improve the prognosis and quality of life of patients with HICH. Multicenter, prospective, randomized, controlled clinical trials are warranted to validate our results.

\section{Acknowledgments}

This study was funded by the Science Technological Innovation Nursery Fund of PLA General Hospital (16KMM14) and the National Natural Science Foundation of China (81271515).

\section{References}

1. Auer LM, Deinsberger W, Niederkorn K, Gell G, Kleinert R, Schneider G, et al: Endoscopic surgery versus medical treatment for spontaneous intracerebral hematoma: a randomized study. J Neurosurg 70:530-535, 1989

2. Basaldella L, Marton E, Fiorindi A, Scarpa B, Badreddine H, Longatti P: External ventricular drainage alone versus endoscopic surgery for severe intraventricular hemorrhage: a comparative retrospective analysis on outcome and shunt dependency. Neurosurg Focus 32(4):E4, 2012

3. Broderick J, Connolly S, Feldmann E, Hanley D, Kase C, Krieger D, et al: Guidelines for the management of spontaneous intracerebral hemorrhage in adults: 2007 update: a guideline from the American Heart Association/American Stroke Association Stroke Council, High Blood Pressure Research Council, and the Quality of Care and Outcomes in Research
Interdisciplinary Working Group. Stroke 38:2001-2023, 2007

4. Chen CC, Lin HL, Cho DY: Endoscopic surgery for thalamic hemorrhage: a technical note. Surg Neurol 68:438-442, 2007

5. Cho DY, Chen CC, Chang CS, Lee WY, Tso M: Endoscopic surgery for spontaneous basal ganglia hemorrhage: comparing endoscopic surgery, stereotactic aspiration, and craniotomy in noncomatose patients. Surg Neurol 65:547-556, 2006

6. Dye JA, Dusick JR, Lee DJ, Gonzalez NR, Martin NA: Frontal bur hole through an eyebrow incision for image-guided endoscopic evacuation of spontaneous intracerebral hemorrhage. J Neurosurg 117:767-773, 2012

7. Feigin VL, Forouzanfar MH, Krishnamurthi R, Mensah GA, Connor M, Bennett DA, et al: Global and regional burden of stroke during 1990-2010: findings from the Global Burden of Disease Study 2010. Lancet 383:245-254, 2014

8. Hemphill JC III, Greenberg SM, Anderson CS, Becker K, Bendok BR, Cushman M, et al: Guidelines for the management of spontaneous intracerebral hemorrhage: A Guideline for Healthcare Professionals from the American Heart Association/American Stroke Association. Stroke 46:2032-2060, 2015

9. Jüttler E, Steiner T: Treatment and prevention of spontaneous intracerebral hemorrhage: comparison of EUSI and AHA/ ASA recommendations. Expert Rev Neurother 7:1401-1416, 2007

10. Keep RF, Hua Y, Xi G: Intracerebral haemorrhage: mechanisms of injury and therapeutic targets. Lancet Neurol 11:720-731, 2012

11. Kuo LT, Chen CM, Li CH, Tsai JC, Chiu HC, Liu LC, et al: Early endoscope-assisted hematoma evacuation in patients with supratentorial intracerebral hemorrhage: case selection, surgical technique, and long-term results. Neurosurg Focus 30(4):E9, 2011

12. Mendelow AD: Mechanisms of ischemic brain damage with intracerebral hemorrhage. Stroke 24 (12 Suppl):I115-I119, 1993

13. Mendelow AD, Gregson BA, Fernandes HM, Murray GD, 
Teasdale GM, Hope DT, et al: Early surgery versus initial conservative treatment in patients with spontaneous supratentorial intracerebral haematomas in the International Surgical Trial in Intracerebral Haemorrhage (STICH): a randomised trial. Lancet 365:387-397, 2005

14. Meretoja A, Strbian D, Putaala J, Curtze S, Haapaniemi E, Mustanoja S, et al: SMASH-U: a proposal for etiologic classification of intracerebral hemorrhage. Stroke 43:2592-2597, 2012

15. Miller CM, Vespa P, Saver JL, Kidwell CS, Carmichael ST, Alger J, et al: Image-guided endoscopic evacuation of spontaneous intracerebral hemorrhage. Surg Neurol 69:441-446, 2008

16. Nagasaka T, Tsugeno M, Ikeda H, Okamoto T, Inao S, Wakabayashi T: Early recovery and better evacuation rate in neuroendoscopic surgery for spontaneous intracerebral hemorrhage using a multifunctional cannula: preliminary study in comparison with craniotomy. J Stroke Cerebrovasc Dis 20:208-213, 2011

17. Nagasaka T, Tsugeno M, Ikeda H, Okamoto T, Takagawa $Y$, Inao $\mathrm{S}$, et al: Balanced irrigation-suction technique with a multifunctional suction cannula and its application for intraoperative hemorrhage in endoscopic evacuation of intracerebral hematomas: technical note. Neurosurgery 65:E826E827, 2009

18. Nakano T, Ohkuma H, Ebina K, Suzuki S: Neuroendoscopic surgery for intracerebral haemorrhage-comparison with traditional therapies. Minim Invasive Neurosurg 46:278-283, 2003

19. Nishihara T, Morita A, Teraoka A, Kirino T: Endoscopyguided removal of spontaneous intracerebral hemorrhage: comparison with computer tomography-guided stereotactic evacuation. Childs Nerv Syst 23:677-683, 2007

20. Ruiz-Sandoval JL, Chiquete E, Romero-Vargas S, PadillaMartínez JJ, González-Cornejo S: Grading scale for prediction of outcome in primary intracerebral hemorrhages. Stroke 38:1641-1644, 2007

21. Sacco S, Marini C, Toni D, Olivieri L, Carolei A: Incidence and 10-year survival of intracerebral hemorrhage in a population-based registry. Stroke 40:394-399, 2009

22. Siddique MS, Fernandes HM, Arene NU, Wooldridge TD, Fenwick JD, Mendelow AD: Changes in cerebral blood flow as measured by HMPAO SPECT in patients following spontaneous intracerebral haemorrhage. Acta Neurochir Suppl 76:517-520, 2000

23. Sun GC, Chen XL, Hou YZ, Yu XG, Ma XD, Liu G, et al: Image-guided endoscopic surgery for spontaneous supratentorial intracerebral hematoma. J Neurosurg [epub ahead of print September 16, 2016. DOI: 10.3171/2016.7.JNS16932]

24. Tao H, Ramadas G, Carrozzella J, Khatri P, Broderick J, Spilker J, et al: Parenchymal hematoma and total lesion volume in combined IV/IA revascularization stroke therapy. $\mathbf{J}$ Neurointerv Surg 4:256-260, 2012

25. van Asch CJJ, Luitse MJA, Rinkel GJE, van der Tweel I, Algra A, Klijn CJM: Incidence, case fatality, and functional outcome of intracerebral haemorrhage over time, according to age, sex, and ethnic origin: a systematic review and metaanalysis. Lancet Neurol 9:167-176, 2010

26. Vespa PM, Martin N, Zuccarello M, Awad I, Hanley DF: Surgical trials in intracerebral hemorrhage. Stroke 44 (6 Suppl 1):S79-S82, 2013

27. Wang WH, Hung YC, Hsu SP, Lin CF, Chen HH, Shih YH, et al: Endoscopic hematoma evacuation in patients with spontaneous supratentorial intracerebral hemorrhage. J Chin Med Assoc 78:101-107, 2015

28. Xi G, Keep RF, Hoff JT: Mechanisms of brain injury after intracerebral haemorrhage. Lancet Neurol 5:53-63, 2006

29. Xu X, Chen X, Zhang J, Zheng Y, Sun G, Yu X, et al: Comparison of the Tada formula with software slicer: precise and low-cost method for volume assessment of intracerebral hematoma. Stroke 45:3433-3435, 2014

30. Yamamoto T, Nakao Y, Mori K, Maeda M: Endoscopic hematoma evacuation for hypertensive cerebellar hemorrhage. Minim Invasive Neurosurg 49:173-178, 2006

31. Zhang HZ, Li YP, Yan ZC, Wang XD, She L, Wang XD, et al: Endoscopic evacuation of basal ganglia hemorrhage via keyhole approach using an adjustable cannula in comparison with craniotomy. BioMed Res Int 2014:898762, 2014

32. Zhou X, Chen J, Li Q, Ren G, Yao G, Liu M, et al: Minimally invasive surgery for spontaneous supratentorial intracerebral hemorrhage: a meta-analysis of randomized controlled trials. Stroke 43:2923-2930, 2012

33. Zurasky JA, Aiyagari V, Zazulia AR, Shackelford A, Diringer MN: Early mortality following spontaneous intracerebral hemorrhage. Neurology 64:725-727, 2005

34. Zuccarello M, Brott T, Derex L, Kothari R, Sauerbeck L, Tew J, et al: Early surgical treatment for supratentorial intracerebral hemorrhage: a randomized feasibility study. Stroke 30:1833-1839, 1999

\section{Disclosures}

The authors report no conflict of interest concerning the materials or methods used in this study or the findings specified in this paper.

\section{Author Contributions}

Conception and design: B Xu, X Xu, Chen. Acquisition of data: $\mathrm{X} \mathrm{Xu}, \mathrm{Li}$, Zheng, Wang. Analysis and interpretation of data: X $\mathrm{Xu}, \mathrm{Chen}$, Sun. Drafting the article: X Xu. Critically revising the article: all authors. Reviewed submitted version of manuscript: all authors. Approved the final version of the manuscript on behalf of all authors: B Xu. Statistical analysis: X Xu, Chen, Zhang. Study supervision: B Xu.

\section{Correspondence}

Bainan Xu, Department of Neurosurgery, Chinese PLA General Hospital, Fuxing Rd. 28, Beijing 100853, China. email: xubn301@163.com. 